\title{
Cloud Standardization: Consistent Business Processes and Information
}

\author{
Răzvan-Daniel ZOTA, Lucian-Alexandru FRĂŢILĂ \\ Bucharest University of Economic Studies \\ zota@ase.ro, alexandru.fratila@csie.ase.ro
}

Cloud computing represents one of the latest emerging trends in distributed computing that enables the existence of hardware infrastructure and software applications as services. The present paper offers a general approach to the cloud computing standardization as a mean of improving the speed of adoption for the cloud technologies. Moreover, this study tries to show out how organizations may achieve more consistent business processes while operating with cloud computing technologies.

Keywords: Business processes, Cloud, Enterprise Architecture, IT Governance, Standardization

1 Introduction

In the current economic climate the governments all over the world try to maximize return on investments on multiple levels. Due to their versatility, cloud technologies may be an important factor in reducing costs and at the same time increasing the value offered by information and communication technologies.

In order to embrace such cloud computing technology implementations, organizations have to consider all the influencing factors.

\section{Current EU Status-Some Proceedings for using Governance and Enterprise Ar- chitecture Frameworks}

At European level there are intense activities to standardize concepts and cloud technologies. In the communication sent by the European Commission - "Unleashing the Potential of Cloud Computing in Europe" [1], are articulated the first European definitions and strategies in this area. According to the European Commission, Cloud Computing is understood as the ability to store, process and access data located on remote systems. In this model, users can assign virtually unlimited computing resources for which they do not need to make major capital investments. Using a business model based on the cloud, even the smallest business can expand to larger markets while governments can make their services more attractive and effective.
Cloud computing is still in its infancy, which allows EC and Europe to innovate and develop the concept.

EC aims to prepare all the industry sectors for adoption of business models based on Cloud systems. These systems can reduce costs, and when combined with digital best practices can increase productivity and stimulate organizations to increase the number of jobs. Thus by 2020 it is estimated that about 45 billion will be spent on Cloud technologies and these will influence GDP by up to 957 billion and create 3.8 million jobs.

Studies carried out by the EC in 2011 shows that if $80 \%$ of organizations would adopt Cloud technologies they could reduce operating costs by $20 \%$, would increase the home working by up to $46 \%$, increase productivity by up to $41 \%$, standardization by up to $35 \%$, new opportunities and new markets penetration by up to $33 \%$.

The unprecedented growth in data flows and data processing technologies over the Internet has a significant impact on the environment through energy consumption, water consumption and greenhouse gas emissions. Cloud technologies could have a major effect in reducing these problems by using resources more efficiently. For example in the U.S. it is estimated that major operators would save \$ 12.3 billion annually if they would adopt Cloud technologies.

Private sector adoption of Cloud technologies in Europe is over $64 \%$ but organizations are still cautious about implementations. The 
general trend is to use hybrid cloud deployment models and testing of non-critical services. This reduces risk but also reduce the potential economic impact of cloud technologies. The main factors contributing to these limitations are legal constraints, security and data protection in the cloud. Therefore most implementations European Cloud deployments are limited to private.

Adoption in the public sector is not very different from the private and concerns are similar. The principal aspects in the public sector are reducing costs and increasing service quality delivered by the Cloud platforms.

According to the study conducted by Capgemini [2] benefits of Cloud technology could be internal: reduce capital expenditures and operating costs of existing systems, improved operational performance of the technology and services, better management and easier, flexibility and better agility, lower upgrade costs, better cost control, the possibility for multiple agencies to share the same data-center. External: services will have a greater focus on citizens; active involvement of citizens and businesses; reducing the cost and complexity of services; service payment is made upon request, depending on usage; better monitoring and transparency of results. With these major benefits observed or estimated, EC determined that cloud technologies are of strategic importance for economic development and reduce the negative environmental impact of economic activities. Consequently, to stimulate the development's Cloud EC has set three major actions covered in its report:

- standardization;

- regulating the terms and conditions for contracts;

- establishing a European Cloud Partnership to support innovation and growth in the public sector.

"Nationally, 55\% of large companies use, in various forms, Cloud computing technologies". This is the conclusion of the study, "Cloud Adoption 2012"commissioned by the CIO Council by company Consult Blue [3]. The results show that Cloud technologies and Romania have passed the critical point, and the percent of adoption will increase in coming years.

The study also shows that, in Romania, although large companies have realized that the true value of Cloud technologies can be exploited only by using the Public Cloud, still focus on developing their own Private Cloud. Therefore, $20 \%$ of respondents use Public Cloud together with Private and only $10 \%$ using only Public Cloud.

According to the study, three reasons stand out as key factors in the decision to use Cloud:

- increase efficiency;

- reduce administration;

- reduce costs.

Although cost reduction represents a major concern for the organizations, it occupies only the third place, which shows that companies are more interested in increasing efficiency and optimization rather than just reducing costs [4].

The study "Cloud Adoption 2012" was conducted by the CIO Council Consult Blue between $21^{\text {st }}$ and $25^{\text {th }}$ of May 2012 and based on the answers given by members of the association.

In Romania there are multiple initiatives for Cloud Computing in several public institutions. But without a legal framework, initiatives are only "internal" or Private Clouds, and can't really benefit from the cutting-edge technologies.

In daily work and studies conducted so far (Digital Agenda - study in 2011, eRomania 2009, Local e-government in Romania) we have identified a number of problems that can be addressed by cloud technologies:

- the multitude of platforms and processes makes collaboration between public institutions difficult;

- lack of a unified platform for public institutions hampers public procurement;

- absence of a unique process of allocation of computing resources results in some institutions having duplicate systems or platforms and in others having not enough resources;

- no transparency on expenditures related to information systems; 
- low elasticity of services offered by IT departments of institutions;

- lack of a single reporting process (collection of documents, statements, etc.);

- lack of standard business management tools of public institutions;

- lack of a unique system for collecting and reporting taxes and / or fines (citizen portal, card payment, etc.);

- difficulties in collaboration with other EU states on issues of eGovernment;

- implementing Cloud technologies within public institutions takes into consideration the creation of a centralized platform, scalable and dynamic, offering high quality IT services at low cost to a level of European security standards. As a result of Cloud technologies implementation, institutions could achieve the following benefits on short or long term;

- provide all electronic services priority to a high level of quality, interoperability is imperative;

- providing a uniform and friendly service with the highest level of safety and confidence;

- availability of services to all, $24 \times 7$ with ubiquitous access, across, or outside the organization;

- achieving a European adoption level rates versus the number of users;

- achieving the EU satisfaction percent average for all electronically supplied services;

- access to information and services through a central integrated access point.

Choosing the right cloud service depends on a lot of factors and complications these services might bring. We take in considerations two categories of factors: business and technical.

Business organizations, who have already implemented or consider implementing appropriate Enterprise Architectures (EA ) and IT Governance, are well placed to take advantages offered by Cloud services - scalability, flexibility, availability and ondemand/pay-per-use utilization of services.
From the technical perspective of the decisional process, the computing model is weighted first considering the depth of configuration needed at the cost of development effort. Second, the storage method is weighted based on volume dynamic of data. Third, communication needs are assessed based on the volume of data and the criticality of information transferred (we will see next why this is very important). All these factors are sided of course by cost considerations compared to classic client-owned infrastructure.

To realize these future requirements is particularly of economic interest: providers aim at providing the user needs and interests in order to ensure that their respective offerings sell. But next to the direct economic exploitation of Clouds, comes the indirect one from the user side: Clouds offer a unique model to outsource tasks, in particular management and administration of resources, thus allowing enterprises to concentrate on their core business, without having to deal with additional administrative tasks. With the Clouds concepts of elasticity, it is furthermore guaranteed that payment reflects interest and usage from the customers - at least to a certain degree.

In general, economic interest focuses in particular on aspects such as scale, elasticity, availability and outsourcing to reduce capital expenditure and to realize payment in relationship to consumption (pay-per-use). Within this section, we will list some of the key economic interests. We will thereby not distinguish between the perspectives from academia, industry and end-user, as this would exceed the scope of this discussion:

a) Provider interest

The primary interest of providers consists obviously in providing better services to their customers, in the sense that they should have increased interest in making use of the offered services. This includes not only higher availability of the application and (its) data, but also all other aspects of quality of interest to the customer.

Moreover, however, this includes specialization and extension of services to provide ad- 
ditional capabilities to the specific users' domain. The attraction for the user thereby consists in easier development of applications in his domain, better performance, or new capabilities.

In addition, providers will want to reduce the cost incurring from maintaining and using their resource infrastructure. This means for one that the management overhead of the large scale of resources should be reduced to a minimum, but second and more importantly, that the utilization of resources is optimized, so that the minimum amount of resources is required for provisioning of the services in the desired quality.

b) Consumer interest

Similarly, the consumers' primary interest consists in easy usage, but in particular in reducing the cost and overhead for maintaining a resource infrastructure.

Infrastructure as a Service allows enterprise users to outsource the infrastructure they need for consuming or offering their own services, thus reducing exactly this overhead in management. But it also offers them a low cost entry point for offering new services, respectively for maintaining an infrastructure, of which the required size is not known a priori. For example, a new service offered to the end-user behind the Cloud consumer, will at initialization time create mixed interest in the community, so that the actual long term requirement of resources is not known.

This equally applies to services and resources consumed within the enterprise environment itself. Through Cloud usage, the number of resources required within the enterprise can be kept to a minimum, extended dynamically with the resources offered by the Cloud host. Thus, the consumer can realize a large resource scope than otherwise possible. Ideally, he will thereby want to realize mixed private public Clouds, where essential data and code is retained at his private site according to their sensitivity.

Next to extending the resource scope, Cloud obviously also offers an extension of the consumer's capabilities to build up new and enhance existing business opportunities.

c) Developer/researcher interest
Finally, developers' and researchers' main interest consists primarily in overcoming the technical obstacles towards realizing the requirements that would in the long run improve the capabilities of Cloud providers. This should thereby respect the specific circumstances of European Cloud provisioning and consumption, as these may differ strongly from the US and China.

Additionally, Clouds offer unique testing environments for researchers and testers without having to acquire and manage an according resource infrastructure locally, thus saving costs and overhead for tests of code systems that show a high degree of scale and dynamicity. With the according support from the infrastructure, this could also cater for adaptability and dynamicity requirements towards the tested service [5].

\section{Governance and Enterprise Architecture Frameworks in the "Clouds"}

According to Gartner, Enterprise architecture (EA) is a discipline for proactively and holistically leading enterprise responses to disruptive forces by identifying and analyzing the execution of change toward desired business vision and outcomes. EA delivers value by presenting business and IT leaders with signature-ready recommendations for adjusting policies and projects to achieve target business outcomes that capitalize on relevant business disruptions. EA is used to steer decision making toward the evolution of the future state architecture.

Also according to Gartner, IT Governance (ITG) is defined as the processes that ensure the effective and efficient use of IT in enabling an organization to achieve its goals. IT demand governance (ITDG-what IT should work on) is the process by which organizations ensure the effective evaluation, selection, prioritization, and funding of competing IT investments; oversee their implementation; and extract (measurable) business benefits. ITDG is a business investment decisionmaking and oversight process, and it is a business management responsibility. IT supply-side governance (ITSG-how IT should do what it does) is concerned with ensuring 
that the IT organization operates in an effective, efficient and compliant fashion, and it is primarily a CIO responsibility.

Cloud Computing is a new business model paradigm - organizations and their business models are shifting from traditional operational focus and moving the operational into the Cloud. "Cloud computing represents a service paradigm that has emerged as a result of distributed computing across the internet" [6]. Usually this help organizations move the focus to innovation. The emerging Cloud technologies are designed to simplify operational processes as users don't have to think on how their service is provided. They just design, provision (size), test and run the service according to their business need[7].

\section{Enterprise Architecture}

A 2012 study done by the Open Group called " Cloud ROI Survey Results Comparison 2011 \& 2012" surveyed IT professionals at the C-level, Director and Manager levels 91.2 percent of whom are either actively researching Cloud Computing for business use or are already implementing Cloud services [1]. The study showed that large enterprises (over 5000 employees) are planning to implement Cloud solutions using a hybrid deployment model in order to reduce costs and improve service quality and elasticity.

This result is relevant to the present study which aims to show that Cloud Computing should be considered in the Enterprise Architectures as one of the main drivers of Cloud initiatives are the Enterprise Architects. The study aims to analyze Cloud Computing as part of the Enterprise Architecture and prove that it should be part of it and that the Cloud Reference Architectures are not enough in a business environment.

\subsection{TOGAF}

"TOGAF is a tool for assisting in the acceptance, production, use and maintenance of architectures. It is based on an iterative process model supported by best practices and a reusable set of existing architectural assets. TOGAF supports the following Architecture types/categories:

- Business Architecture: The business strategy, governance, organization, and key business processes;

- Data Architecture: The structure of an organization's logical and physical data assets and data management resources.

- Application Architecture: A blueprint for the individual application systems to be deployed, their interactions, and their relationships to the core business processes of the organization;

- Technology Architecture: The logical software and hardware capabilities that are required to support the deployment of business, data, and application services. This includes IT infrastructure, middleware, networks, communications, processing, and standards" [8].

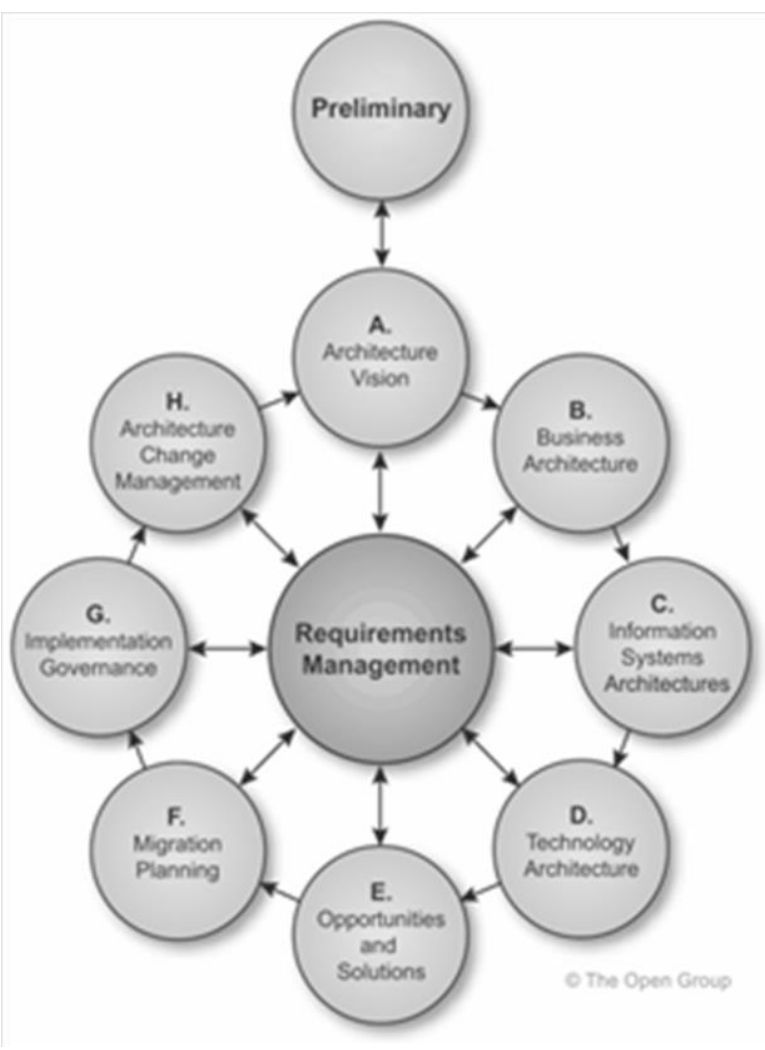

Fig. 1. TOGAF Architecture Development Method

\subsection{PEAF}

"PEAF bridges the gap between minimal "EA Frameworks" which do not provide a complete set of what is required or huge monolithic "EA Frameworks" that are too difficult to understand and difficult to use. Pragmatic EA claims to be better than other 
frameworks covering the whole enterprise and also claims more simplicity by being less complex, therefore, more applicable to real life scenarios.

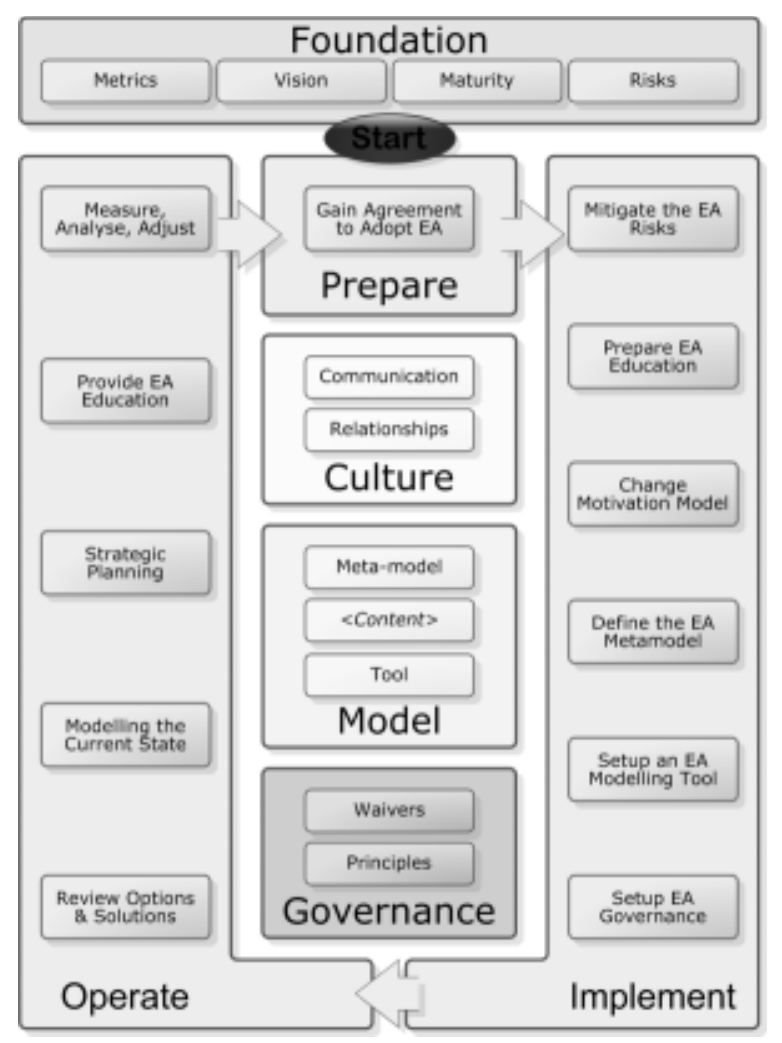

Fig.2. PEAF Framework

PEAF is composed of two fundamental parts, products and processes. The Products part contains all the products required for an EA initiative:

- Foundation - Provides the products required for starting and/or continuing an existing EA initiative;

- Culture - Communication and relationships are the key to EA. Without them and their under-standing, everything else is superfluous;

- Model - The main artifact of EA represented by the models which allow information to be gathered viewed and analyzed;

- Governance - Providing an environment to guide change as it happens throughout the organization;

- The Processes part contains all the processes required for an EA initiative divided into 3 distinct phases:

- Prepare - Scoping and gaining approval for an EA initiative;

- Implement - Making changes to prepare the organization to operate EA.

- Operate - Doing EA" [8].

\subsection{Common Characteristics}

These two architecture frameworks have a structured development approach, TOGAF has its Architecture Development Method (ADM) and PEAF has the Products and Processes. TOGAF ADM is a process that has a phased iterative approach which goes through a range of architectural do-mains to meet the business requirements. PEAF, through Products and Processes has a holistic approach to Enterprise Architecture. This holistic and structured approach assists the organizations step by step to create, communicate, implement and run an EA. There is no right or complete choice of the framework. Depending on the time and resources that could be allocated on a Cloud project, or EA initiative organizations should focus more on the long term result that most benefit them. Both architecture frameworks have coverage in the areas organization need to oversee in a Cloud deployment.

\section{IT Governance}

Current EU and Romanian regulations imperatively demand for a Governance framework within organizations, especially in the Public Sector. Governance has been around for many years, both in business and IT. One such framework is CobIT (Control Objectives for Information and related Technology).

"CobIT is a best practice framework that lays out a set of generally accepted measures, indicators, and processes. These assist managers, auditors, and IT users in maximizing the benefits derived through the use of information technology and in developing appropriate IT governance and control within an organization"'[9].

\section{Service Management, Reference and} Technical Architectures

Looking at IT Service Management (ITSM) from a bottom up perspective of the standard- 
ization process, it can offer the architect the insight on how is IT serving the business.

Reference Architecture (RA) is the model by which we develop services. It should contain the overall picture of a typical Cloud service. Let's say we want to have a SaaS document management system. In the RA we should have the exact scenario, processes and technology to have a SaaS DMS.

Technical architectures in the Cloud implementation process should be standard templates or platforms of hardware and software. Considering the above example of the SaaS DMS, the technical architecture should define a number of standard server, networking, storage and archiving templates.

\section{Conclusions}

According to the EC study "Advances in CloudsExpert Group Report - Future Cloud Computing" [10], the future IT infrastructure is growing extremely in size and heterogeneity. An increasing number of users make use of online services of all kinds and more and more applications exploit the benefits of data and code outsourcing for improved maintenance and availability.

This leads to an increasing load on networks and servers, which in turn are constrained in terms of bandwidth, latency, performance etc. Service and resource providers all over the world need to ensure that they can deal with this increasing amount of usage in a most cost-effective way and respecting the given restrictions and limitations. Though automated resource management capabilities have increased considerably over time, they are still insufficient to deal with the expected scope and heterogeneity.

Moreover, the need for resources will exceed the availability of individual providers, in particular if they cannot afford to host large scale infrastructures such as major US providers do. In particular for business processes and services spanning multiple providers, a simple Cloud provisioning model is insufficient. Similarly, maintaining availability under mobile and widely dispersed constraints requires exploitation of Cloud providers from other countries to extend the local infrastruc- ture. The globalization of the internet therefore can only lead to a globalization of the Cloud ecosystem, too - on all levels. This equally implies technical, economical, legal and political concerns. Current federation and interoperability support is still too weak to realize this, though.

Diversity is thereby not restricted to the types and qualities of the Cloud offerings that users may want to integrate into a single system, but is also affected by the growing heterogeneity of device and client platforms, data structures, applications and even operating systems (Windows, Mac, Linux, Android, iOS etc.). In order to reach a large customer base, providers must therefore host environments that are highly adaptable and offer a wide scope of interoperability and portability.

Even though the number of processing units and thus the implicit performance at least for multi-task execution is constantly increasing, mobile devices nonetheless will outsource most of their processing towards the internet. The clients thus effectively resemble browsers more and more, where comparatively little computation and data handling is executed locally, so that the hosts need to cater for the main processing, but implicitly also for the communication. The average user typically also owns multiple devices between which he wants to share his data and ideally also his applications and working environment. With this comes the demand for constant online availability - disregarding technical deficiencies.

As we previously discussed in paper[4], organizations have to consider a framework and it is very likely to see EA as a trend in the coming years of Cloud Computing. One such frameworks that we considered is TOGAF.

Also, due to the fact that business data and processes are hosted outside the organizations, modeling the EA is not enough. Organizations have to keep a tight control on its processes and assets and here is where ITG comes in place.

In the earlier versions of both TOGAF and CobIT, the community accepted notion was 
that Enterprise architecture was a part of the Governance framework. Recent updates and studies have shown that Enterprise Architecture and IT Governance bind together closer.
TOGAF 9 is not about IT anymore but about the whole business organization, therefore ITG - CobIT in this case -, is and should be a part of the EA.

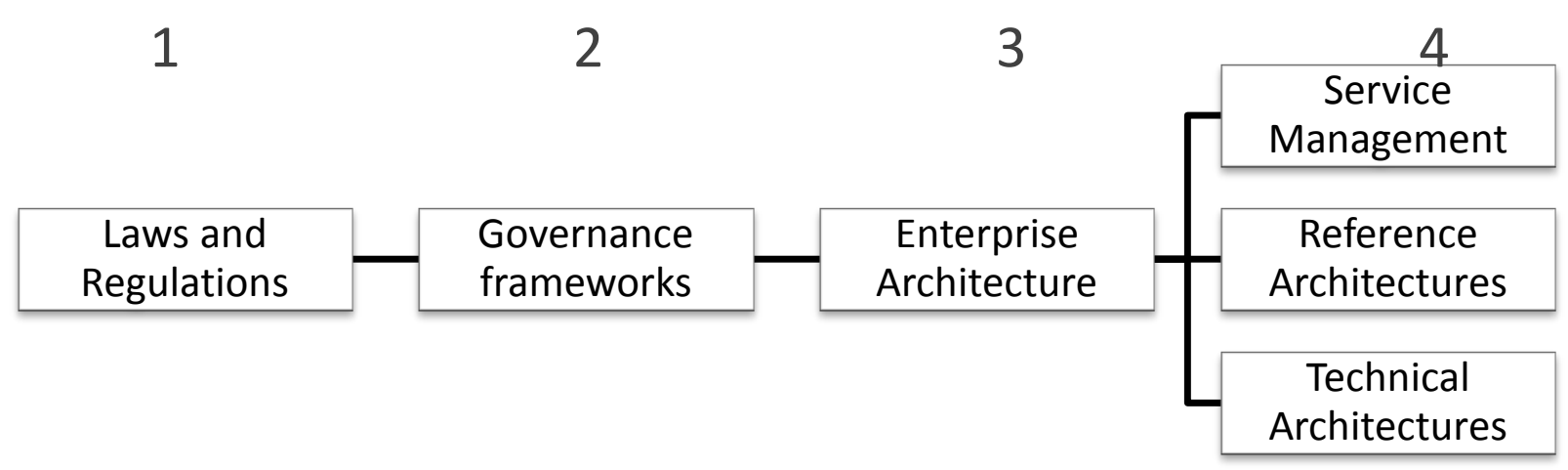

Fig. 3. "Standard" Cloud adoption steps

Until EU defines regulations regarding Cloud Computing for both Public and Private sector, organizations should consider the above steps.

On the first step the organization should identify the laws and regulations that govern their activity. Once the organization has identified the regulations, they can understand how they will affect the new Cloud business model. For example hosting private user data might be regulated and that data could be stored only under special conditions.

In the second and third phases the organizations should be choosing the appropriate frameworks.

Only when Governance and EA are defined, organizations should move to step four, chose technical architecture model and implement proper service management for the new Cloud services. Proper Service Management will enable organizations to take advantage of the Cloud characteristics.

The approach represented in Figure 3 is a thorough approach to Cloud Computing implementations and should be noted that it could be very resource demanding and time consuming. We consider that it is the "safest" way for large organizations to approach Cloud implementations. From this approach it should also be noted that the main emphasis is on the business and business model and the regulations governing it. Cloud computing is regarded from the business perspective of Enterprise Architectures and it is a key business driver and not just a technology piece of architecture.

The thorough exploration of the implementation process can improve the consistency of a business process wherever it is running because organizations will have total visibility and control of that process.

Figure 4 depicts a simple example of a ticketing process. It has been depicted in a tiered model in order to better illustrate the need of architecture and governance.

Considering the simple ticketing process in the Figure 4, we note that in such a tiered model, once we have the architecture and the governance of the process it will be less important for the end user as well as to some applications, where the components are running. 


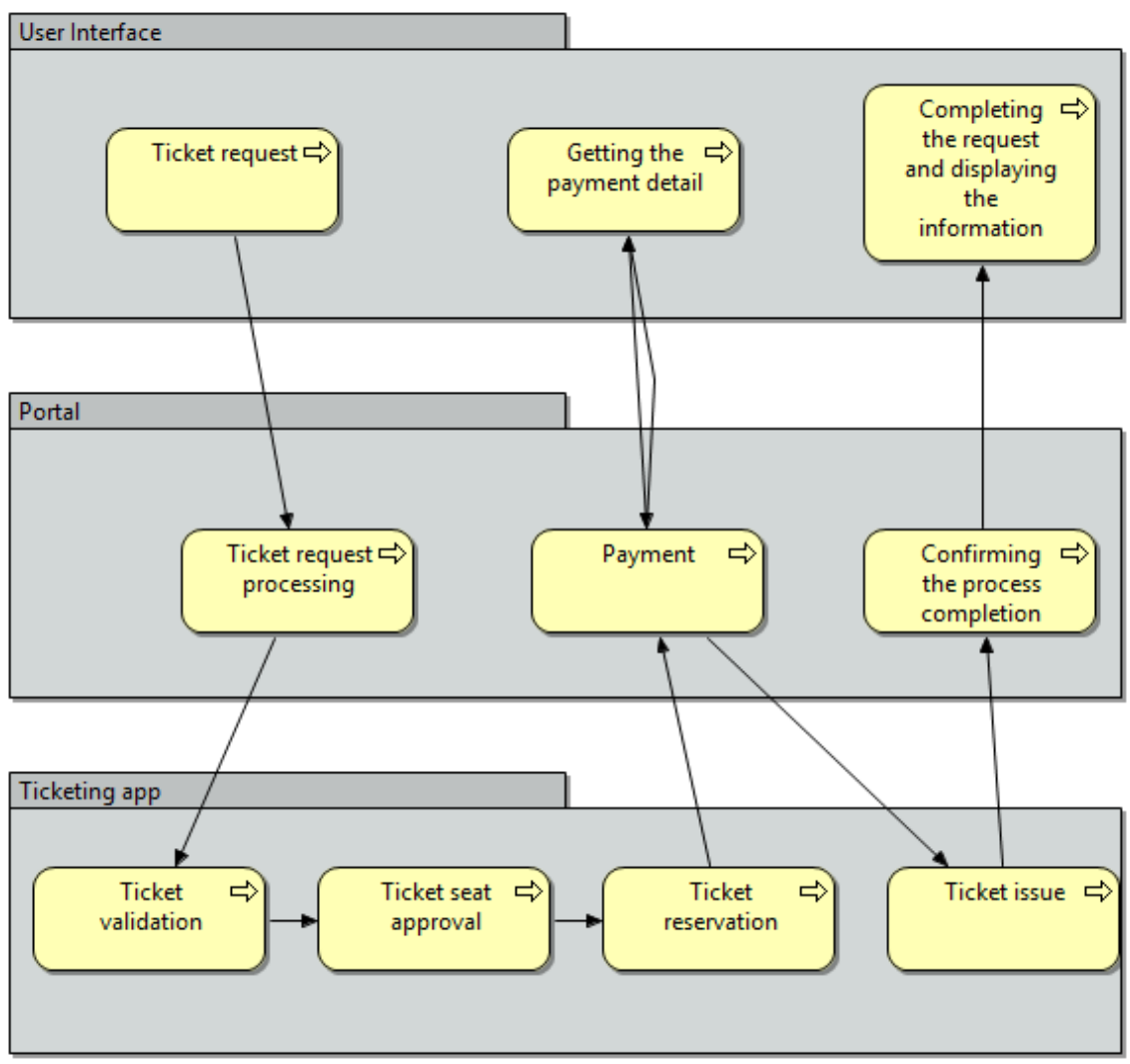

Fig. 4. Simple ticketing process

For the previous example, certain events we might consider running resource intensive steps of the process in the Cloud. Knowing the exact map of that process will help determine the resources needed from a Cloud provider, the controls and the KPIs to measure its performance. Based on this approach an organization could run seamless the process or any of its components in the Cloud.

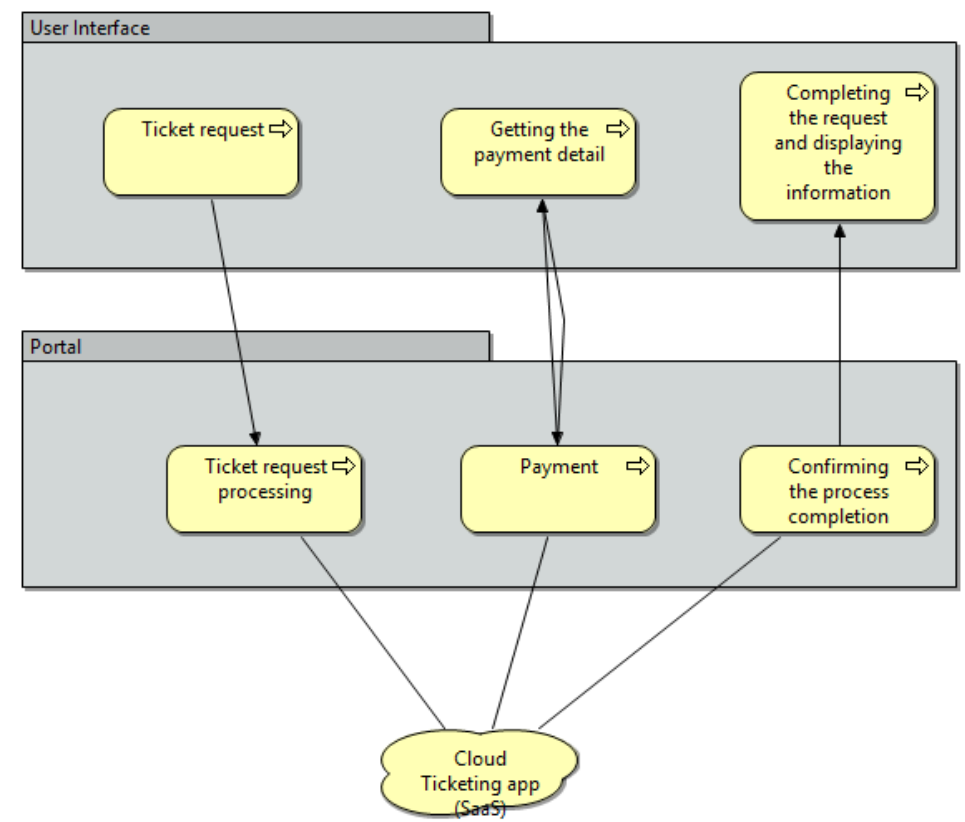

Fig. 5. Cloud simplified process 
In Figure 5 we may notice that the process has been simplified. The ticketing application has been replaced by a service provided by a third party. The end user is not affected and aware of the change and it will get the same experience in terms of usability and performance.

From the organization's perspective the process is now simplified and optimized. The implementation of the new application in the Cloud should have simplified the process being cost-efficient at the same time.

Cloud implementations are not cost efficient, practical, secure and easy to use at all times. Therefore, a careful planning should be made as mentioned before. In the same time, organizations may use the information gathered in documentations like "Building Return on Investment from Cloud Computing" released by The Open Group [11].Cloud Computing can provide many advantages over conventional approaches to IT provisioning, which can translate into significant improvements in ROI. But what makes it particularly exciting is that its potential effect on business is not just incremental improvement, but disruptive transformation through new operating models.

The white paper [11] provides an analysis of how to build and measure ROI that will help businesses to reap the benefits of Cloud Computing, and take advantage of its potential for incremental improvement and disruptive transformation of business processes.

Cost efficiency is sometimes disregarded as pay-per-use models might sometimes confuse organizations. For example a price per hour, gigabyte and so on might sometimes bring higher costs because poor calculations. Some very good examples of cost calculation are done in [12].

Finally, overall, the adoption of cloud computing seems to be beneficial: as the new technologies become available to a cloud vendor, the applications and customers will take advantage immediately from it, without any investment in capital. For example, the unrelenting growth of the Amazon Web Services (AWS - Amazon cloud computing division) has made possible an unbelievable in- crease in the number of new services added: just in 2012, 159 of new services and features were added to the AWS [13].

\section{References}

[1] "Unleashing the Potential of Cloud Computing in Europe" http://ec.europa.eu/in formationsociety/activities/cloudcomput ing/docs/com/swd_com_cloud

[2] Capgemini immediate, "A New Approach for a New Business Landscape", Available: http://www.uk.capgemini.com/ sites/default/files/resource/pdf/Capgemini _Immediate__A_New_Approach_for _a_New_Business_Landscape.pdf

[3] V. Bîrzoi, "Jumătate din companiile mari din România folosesc deja cloud computingul", 30 May 2012, Available: http://www.businesscover.ro/30-05-2012jumatate-din-companiile-mari-dinromania-folosesc-deja-cloudcomputingul/

[4] "Companiile din România mizează pe tehnologia cloud computing", http://www.eurocloud.ro/companiile-dinromania-mizeaza-pe-tehnologia-cloudcomputing/

[5] L. Schubert, J. Keith, B. Neidecker-Lutz, "The future of cloud computing - Opportunities for European cloud computing beyond 2010", Expert Group Report, Available: http://cordis.europa.eu/fp7/ ict/ssai/docs/cloud-report-final.pdf

[6] R. Aoun et. al., "Towards an optimized abstracted topology design in cloud environment," Future Generation Computer Systems, Elsevier, vol. 29, pp. 46-60, April 2012

[7] R. Zota, A. Frăţilă, „Toward the Selection of an Enterprise Architecture Model for a Cloud Environment", Proceedings of the 11th IEEE RoeduNet Conference, Networking in Education and Research, Sinaia, pp. 170-175, 17-19 January 2013, ISSN-L 2068-1038

[8] The Open Group, TOGAFTM Version 9.1, "A Pocket Guide", Available online at: www2.opengroup.org, December 2011

[9] CobIT, www.isaca.org/cobit/ [last access in June 2013] 
[10] European Commission, "Advances in Clouds - Research in Future Cloud Computing", May 2012, Available: http://cordis.europa.eu/fp7/ict/ssai/docs/f uture-cc-2may-finalreport-experts.pdf

[11] M. Skilton et. al., "Building Return on Investment from Cloud Computing", The Open Goup, Available: http://www.opengroup.org/cloud/whitepa pers/ccroi/exec.htm

[12] M. Armbrust et. al., "Above the Clouds:
A Berkeley View of Cloud Computing, EECS Department", Technical report, February 2009, Available: http://www.eecs.berkeley.edu/Pubs/Tech Rpts/2009/EECS-2009-28.html

[13] M. Tremante, "Amazon Web Services' growth unrelenting", May 2013, Available: http://news.netcraft.com/archives/ 2013/05/20/amazon-web-servicesgrowth-unrelenting.html

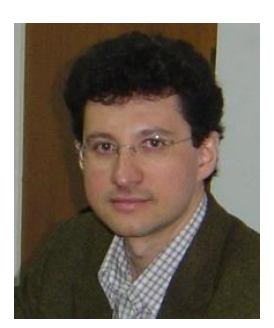

Razvan Daniel ZOTA was born in Bucharest, Romania, in December 1967. He received the B.S. degree in Computer Science from the University of Bucharest, Faculty of Mathematics in 1992, the M. S. degree in Management from the National School for Political and Administrative Studies in 1994. He received, also, the B. S. in Finance and Accounting and Ph.D. degree in Economic Informatics and Cybernetics from Bucharest University of Economic Studies in 1999 and 2000. He is full professor at the Department of Economic Informatics and Cybernetics since 2006 and Ph. D. advisor in Economic Informatics since 2010 at the Bucharest University of Economic Studies. Current research interests include business applications and models used in Cloud Computing, SOA business applications, business process modeling, e-business applications. His research publications record includes 28 papers published in peer-reviewed journals and 72 papers presented at international conferences and published in conference proceedings. He is editorial member for Economic Informatics journal from the Bucharest University of Economic Studies and for several international conferences.

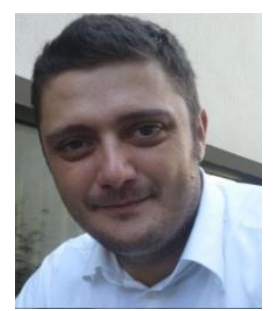

Lucian-Alexandru FRĂŢILĂ was born in Bucharest, Romania, in August 1981. He received his B.A. degree in Economics from Bucharest University of Economic Studies, Department of Economic Informatics and Cybernetics in 2006. He has over 10 years working for international companies like IBM, HP and CompTIA, having multiple roles. Currently he's a student in the Doctoral School of the Bucharest University of Economic Studies researching new architectures and business models in the field of Cloud computing. He is also an independent Consultant and Subject Matter Expert in projects related to Cloud Computing. He actively contributed in the development of Cloud certification exams for CompTIA. 